\title{
Emotional Understanding and Color-Emotion Associations in Children Aged 7-8 Years
}

\author{
Debbie J. Pope, ${ }^{1}$ Hannah Butler, ${ }^{2}$ and Pamela Qualter ${ }^{3}$ \\ ${ }^{1}$ Department of Psychology, Edge Hill University, Ormskirk, Lancashire L39 4QP, UK \\ ${ }^{2}$ Division of Clinical Psychology, University of Manchester, Manchester M13 9PL, UK \\ ${ }^{3}$ School of Psychology, University of Central Lancashire, Preston, Lancashire PR1 2HE, UK \\ Correspondence should be addressed to Debbie J. Pope, debbie.pope@edgehill.ac.uk
}

Received 24 October 2012; Accepted 22 November 2012

Academic Editor: Annie Vinter

Copyright (C) 2012 Debbie J. Pope et al. This is an open access article distributed under the Creative Commons Attribution License, which permits unrestricted use, distribution, and reproduction in any medium, provided the original work is properly cited.

\begin{abstract}
An understanding of the development of emotional knowledge can help us determine how children perceive and interpret their surroundings and color-emotion associations are one measure of the expression of a child's emotional interpretations. Emotional understanding and color-emotion associations were examined in a sample of UK school children, aged 7-8 years. Forty primary school children (mean age $=7.38$; $\mathrm{SD}=0.49$ ) were administered color assessment and emotional understanding tasks, and an expressive vocabulary test. Results identified significant gender differences with girls providing more appropriate and higher quality expressions of emotional understanding than boys. Children were more able to link color to positive rather than negative emotions and significant gender differences in specific color preferences were observed. The implications of adult misinterpretations of coloremotion associations in young children are discussed.
\end{abstract}

\section{Introduction}

An understanding of the development of emotional knowledge and an awareness of age-appropriate effective milestones are essential for professionals working closely with children [1]. How children develop and achieve their emotional knowledge can help professionals understand how children perceive and interpret their environment, and how they respond, manage, and organise their own feelings in emotive situations $[2,3]$. Through such intelligence, effective programmes of learning and treatment can be put in place within educational and clinical settings to provide the opportunity for children to explore their emotional relationships and help achieve their developmental milestones $[4,5]$. Against a background of research into children's emotional understanding, this study investigates the identification and expression of emotions and the influence of color-emotion associations in a sample of children, aged from 7 to 8 years but first, a brief overview of the growing emphasis on the importance of emotional health and well-being will be provided.

In the UK, there is a significant and growing national awareness of the importance of the emotional development within clinical and educational settings, with a growing body of research and increasing resource commitments by central government. School-based interventions such as SEAL (UK: Social and Emotional Aspects of Learning) and PATHS (USA: Promoting Alternative Thinking Strategies) are designed to help children increase their awareness and use of emotional skills to enhance their ability to function appropriately within social situations [6, 7]. In February 2009, the UK Departments of Health (DH) and Children, Schools, and Families (DCSF) issued a joint Departmental Strategic Objective outlining future plans to promote the emotional health and well-being of children [8] and, following recommendations by the Child and Adolescent Mental Health Service (CAMHS), a National Advisory Council was established for children's mental health and psychological well-being [9].

A child's emotional understanding comprises an ability to recall and explain their own emotional experiences and an ability to recognise emotion in themselves and in other people $[2,5,10]$. However, the understanding of complex emotions requires higher cognitive social-emotional skills in order to interpret social cues within a situation, as well as being able to fully understand and recognise emotional contexts [4]. 
Emotional understanding and knowledge of the process and translation of emotions become apparent at the age of two or three with emotion-descriptive language beginning to appear alongside basic vocabulary $[11,12]$. A lack of emotion-descriptive language by the end of the child's second year, an inability to react appropriately to social cues (which may be displayed through behaviours) or reduced understanding of the reactions of others to situations, can be significant indicators of diminished child emotional growth and can potentially underlie subsequent behavioural problems $[4,10,11]$. In turn, this can lead to a heightened susceptibility of psychopathology and emotional disorders [12].

Language and verbal ability are strongly associated with emotional understanding $[5,13]$ as children perceive and interpret events, with language functioning not only as a communication tool, but also as a way of shaping thoughts [14]. In order to be able to interpret emotional expression, a child needs first to be able to utilise knowledge and understanding of such expression to be capable of expressing this understanding in appropriate language [15]. A child's emotional and social development is shaped by the language used in a descriptive conversation about a person's unobservable mental states (i.e., their goals, thoughts, and feelings about a situation, which are intimately used to decode and understand, own and other peoples' behaviors) [10] and as children develop they begin to increasingly experiment with, and use, the more complex emotions [16]. Whilst females often perform better than males on tests of language and verbal ability at all ages, they also consistently score higher than males on tests of emotional awareness, even when controlling for verbal intelligence [17]. Girls as young as 3 years have demonstrated higher levels of emotion labelling and understanding of complex emotions than boys, independent of vocal ability $[18,19]$.

Whilst expressive language ability has associations with emotional understanding, other measures of creativity, such as drawing, have also been used as measures of social and emotional adaptation [20]. Drawing is an enjoyable, natural activity which can be used as a means of expressing emotion and feeling [21-23] and art therapy techniques are increasingly used by practitioners to explore children's perceptions of events, particularly those suffering from physical and mental health problems [24, 25]. For example, the Color Inkblot Therapeutic Storytelling method (CITS) requires a person to a choose colored ink, make inkblots, and create a story in relation to these colors and shapes. This technique is particularly effective for those with a cultural resistance to talk about emotions [26]. Further psychological studies analysing the contents of children's drawing and interpreting the results on projective measures to depict relationships between emotional meaning and status are well documented [27].

The way that color is used within drawings can reflect and emphasize particular emotional states or qualities of the artist [28] with children using color in their artwork as a means of expressing their underlying emotional status. Generally, it is believed that bright colors emphasize positive qualities and dark colors emphasize negative qualities [27, 29]. However, it has been found that when children were asked to state their color preference first, this was then reflected in the colors used to express certain emotions, rather than the assumed color associations for negative (dark) and positive (bright) presentation. Therefore, least preferred colors were related to negative associations and preferred colors used to express something positive. This suggests that the translation of color into an emotional meaning is both personal and subjective and any interpretation of color use should only be made alongside the knowledge of color preference [28].

From infancy, specific colors develop "learned" paired associations with meanings and emotions. These associations or schemas can remain throughout life eliciting automatic emotional response, thoughts and action without any conscious awareness [30,31]. Within the everyday environment, children are exposed to a considerable amount of vibrant color through toys and possessions, all of which can carry certain messages and associations [30, 32]. From early infancy children are also exposed to particular colors by parents and family, such as the stereotypical gender-color associations: blue for boys and pink for girls [30]. The colors used in everyday society may have a substantial influence on how children develop emotional associations to colors; associations which strengthen with maturity [28]. School age is also a very influential time when children are flooded with several colors of meaning and where specific emotional associations are formed [33]. In support of this, it has been found that within certain settings some colors can have a universal language and meaning understood by cross-generational and sociocultural populations [29]. Reinforcement occurs throughout life, and it follows that the more a child is exposed to a color-emotion pairing, the stronger the internal representation for that color is further embedded [34].

Color can have an important role within the mental health setting in enabling both therapeutic interpretations of emotional state and also as an intervention aid to facilitate exploration of emotion. An analysis of children's drawings with a life-threatening illness found significant differences in their choice of color in comparison with that of "healthy" children [29], with their negative situation being reflected in the extensive use of "black". In the same way, pictures drawn by children receiving therapy for trauma have also tended to show a lack of bright color and an extensive use of black [35].

Color appears to be context appropriate with different situations and colors reflecting different emotions, thoughts, and behaviours [31]. It has been suggested that there is a reciprocal interaction between color and emotion, with particular feelings being associated with color, and the combination of cognition that affect all bringing memories, feelings, and emotions to the forefront [29]. The colors of toys, drawing and coloring behaviors, and the language used within the environment may all contribute towards a child's emotional literacy and understanding [36].

However, the interpretation of color in pictures or art, and the associated emotional significance, is contentious and subjective $[21,27,28]$. Some studies studying color-emotion links have been criticised for not using evidence-based practise to inform their research [31]. In particular, subjective methods, whereby participants are asked to recall colors, or depict color verbally rather than a physical presentation, 
has led to problems in the interpretation of the relationship between color and emotion [37]. For instance, "red" has been found to convey considerable ambivalent emotional association as it can be associated positively with warmth, love, and happiness or negatively to represent danger, anger, and sadness [30,31]. There is often a lack of knowledge of the artists preferences towards individual colors [28] and context and environment have not been taken into account when presenting the color sample [38]. Without this specific and broader knowledge researchers can misinterpret the use of color as a result of their own idealisations and societal assumptions.

The use of color interpretation and emotional association has the potential to become a useful tool in the clinician's armoury for intervention and treatment. Nevertheless, what is also evident is that any interpretation can be highly subjective. This study explored emotional understanding in boys and girls, aged 7-8 years by assessing their ability to discuss, identify, and recognise basic and complex emotions. We also investigated the impact of color preference in color-emotion associations in order to develop further understanding of how colors can interact with, and potentially be used as a measure of, emotional experience.

\section{Method}

2.1. Participants. Forty children ( 15 girls and 25 boys) aged between 7 and 8 years old $(M=7.38, \mathrm{SD}=0.49$, age range 7.10-8.30) from two classes within a mainstream primary school in the North East of UK formed the sample for this study. Letters detailing the study were sent home with the children, and an informed consent was obtained from parents. Verbal consent was obtained from the children at the beginning of the study.

\subsection{Measures}

2.2.1. The Kusche Affective Interview-Revised (KAI-R) [39]. The Kusche Affective Interview [39] assesses childrens emotional understanding in relation to a range of affective states and situations and has been used extensively in both developmental and clinical research [12]. Children are asked to provide examples of times they have felt ten commonly encountered emotions (five basic emotions: happy, sad, mad, scared, love, and five more complex emotions: proud, guilty, jealous, nervous/anxious, and lonely). Children are then asked to provide an example of when another person had felt that emotion. Due to time constraints and ethical concerns by teachers, we included six of the original emotions within this study (three basic emotions: happy, sad and love, and three complex emotions: proud, jealous and nervous). All coding and analyses were conducted inline with other studies using this measure.

Children's understanding of these six emotions was assessed by measuring their ability to discuss emotional experiences, to identify the six emotional states in themselves, and to recognise emotional states in other people. Children were asked to provide examples of experiences where they have felt the six specific emotions (happy, proud, love, sad, nervous and jealous).

To assess the children's ability to discuss emotional experiences they were asked "tell me about a time when you felt..." (happy, proud, love, sad, nervous, and jealous). To determine children's ability to identify emotional states in themselves they were asked "How will you know when you are feeling..." (happy, proud, and love, sad, nervous, and jealous) and to gain an understanding of the children's ability to recognise emotional states in others, they were asked "how do you know when other people are feeling. .." (happy, proud, love, sad, nervous, and jealous). If no response was provided, or they were having difficulty in answering the question, they were asked to think of an example of when another person had felt that emotion.

All responses were recorded and coded independently by two independent raters.

The raters scored the responses for the appropriateness and quality of answer. The appropriate answers were rated as (3) an appropriate example, (2) an unrelated example, (1) denial that they had ever felt that way, and (0) "I don't know." The quality of response was rated as: (2) shows a good knowledge of the emotion, (1) little detail and (0) no response, "I don't know." Kappa coefficient was used as a measure of interrater agreement. The kappa coefficient on the 40 transcriptions was 0.86 for the appropriateness of examples given and 0.99 for the quality of answer. Raters discussed all disagreements before reaching consensus and finalising their ratings.

Emotions were grouped into either positive (happy, proud, and love) and negative categories (sad, nervous, and jealous) or basic (happy, sad, and love) and complex (proud, jealous, and nervous) categories. Scores were totalled for each of the three categories of emotional experience and for each rater to give an overall appropriate and quality score for each grouping (positive/negative and basic/complex).

2.2.2. Color Assessment [28]. This measure provided ratings of children's feelings towards individual colors and evaluated general color-emotion associations towards fictional characters within emotion-eliciting stories.

In Part 1 of the task, the children were shown 10 rectangular cards $(11 \mathrm{~cm} \times 11 \mathrm{~cm})$ of varying colors (red, orange, yellow, green, blue, purple, pink, white, brown, and black). Colours were fully saturated and varied on hue and value (see Table 1 for precise color notation) [40].

After each card presented the children were asked to independently rate on a five-point smiley-face Likert scale how the color made them feel (ranging from "very happy" to "very unhappy"). The researcher purposely did not name the color to prevent any potential color name bias.

In Part 2 of this task, the children were given the same colors, as previously rated in the first task, as felt tip marker pens. The colors of the pens were chosen by the researcher to match, as closely as possible, the color of the cards used in Part 1. Children were also provided with a response booklet on which to record their responses. Three stories involving the six emotions (happy, proud, love, sad, nervous, and jealous) were read to the children. All the stories were 
TABle 1: Card colour samples specified according to the Munsell system of colour notation [40].

\begin{tabular}{lcrc}
\hline Colour Name & Hue & Value & Chroma \\
\hline Red & $7.5 \mathrm{Y}$ & 4 & 14 \\
Orange & $2.5 \mathrm{YR}$ & 6 & 12 \\
Yellow & $5 \mathrm{Y}$ & 8 & 12 \\
Green & $10 \mathrm{GY}$ & 5 & 12 \\
Blue & $10 \mathrm{~B}$ & 4 & 10 \\
Purple & $7.5 \mathrm{P}$ & 4 & 10 \\
Pink & $5 \mathrm{RP}$ & 8 & 6 \\
Brown & $5 \mathrm{YR}$ & 4 & 8 \\
Black & $\mathrm{N} \mathrm{0}$ & - & - \\
White & $\mathrm{N} 10$ & - & - \\
\hline
\end{tabular}

selected from an age-appropriate children's book [41]. The stories did not explicitly mention the emotion but the emotion was clearly alluded to within the story.

At the point where one of the six emotions was being experienced by a fictional character, the story was stopped and the children asked to choose a colored pen and circle the $\mathrm{X}$ next to the appropriate letter $(A, B, C, \ldots$, etc. $)$ within their response booklet (a white pen was available with uniquecolored ink if the children wished to choose "white" so that when coding, it was clear that "white" had been chosen). The researcher purposely did not mention the name of the emotion to prevent any color bias towards the specific emotional word. The children were given the opportunity to state "I don't know" if they could not choose an appropriate color and throughout this task children were reassured that there were no wrong answers and to select a color on the basis of which came to mind first.

2.2.3. Expressive One Word Picture Vocabulary Test (EOW$P V T$ ) [42]. The Expressive One Word Picture Vocabulary Test (EOWPVT) is an individually administered, norm referenced test that provided a measure of speaking (expressive) vocabulary. The EOWPVT requires approximately 10 to 15 minutes to administer and is not timed. Children were presented with a series of progressively more difficult illustrations that depicted an object, action, or concept and the child was asked to name each illustration (prompts and cues could be given by the examiner). When a child was unable to name a number of consecutive illustrations, testing was discontinued. The raw scores obtained for each child were then compared to defined norms in order to obtain a standard EOWPVT score for each child.

2.3. Procedure. The study comprised of two separate sessions (two days apart) when the children worked independently with the researcher. Session 1 involved taking children, in turn, out of the classroom and conducting the color assessment tasks which lasted between 20 and 30 minutes per child. Session 2 was administered on a separate day and required working with the children individually in a quiet section of the classroom on the KAI-R task and the EOWPVT. This took approximately 30 minutes per individual. All the scoring for the second session was done after the administration of the tests by two independent raters who were unaware of the topic of the study or the children's performances on previous tasks.

\section{Results}

There were no significant age differences $(t(38)=0.25, P=$ $0.81)$ between boys $(M=7.36, \mathrm{SD}=0.49)$ and girls $(M=$ $7.40, \mathrm{SD}=0.51)$. There were also no significant differences in expressive vocabulary (EOWPVT) scores $(t(38)=0.95$, $P=0.35)$ between boys $(M=75.16, \mathrm{SD}=15.76)$ and girls $(M=78.60, \mathrm{SD}=10.04)$. Therefore, further analyses including gender could be conducted without the confounding influence of age or expressive vocabulary ability.

3.1. Kusche Affective Interview-Revised (KAI-R) and Gender. Emotions were grouped into either positive (happy, proud, and love) and negative categories (sad, angry, nervous) or basic (happy, sad, and love) and complex (proud, nervous, and jealous) categories. Descriptive statistics for each of these categories are given in Table 2.

A series of $2 \times 2$ mixed ANOVAs were performed to investigate gender differences on the appropriate and quality responses of both the positive/negative and the basic/complex groupings.

There was a significant main effect of gender for both appropriateness $\left(F(1,38)=4.72, P=0.036, \eta^{2}=0.110\right)$ and quality $\left(F(1,38)=4.99, P=0.031, \eta^{2}=0.116\right)$ of response for positive/negative emotions with girls providing more appropriate and better quality answers for both positive and negative emotions. There was no significant main effects of grouping, that is, no differences between responses for positive and negative emotions (appropriate: $F(1,38)=0.45$, $P=0.505, \eta^{2}=0.012$; quality: $F(1,38)=2.90, P=0.097$, $\left.\eta^{2}=0.071\right)$ and there were no significant interaction effects between positive/negative grouping and gender (appropriate: $F(1,38)=1.63, P=0.210, \eta^{2}=0.041$; quality: $F(1,38)=$ 2.61, $\left.P=0.115, \eta^{2}=0.064\right)$.

There was a significant main effect of gender for both appropriateness $\left(F(1,38)=4.72, P=0.036, \eta^{2}=0.110\right)$ and quality $\left(F(1,38)=4.99, P=0.031, \eta^{2}=0.116\right)$ of response for basic/complex emotions with girls providing more appropriate and better quality answers for both basic and complex emotions. There were also a significant main effect of grouping with more appropriate and better quality responses being provided for basic emotions compared to complex emotions (appropriate: $F(1,38)=18.69, P<0.001$, $\eta^{2}=0.330$; quality: $F(1,38)=12.30, P=0.001, \eta^{2}=$ $0.245)$. There were no significant interaction effects between basic/complex grouping and gender (appropriate: $F(1,38)=$ $0.04, P=0.841, \eta^{2}=0.001 ;$ quality: $F(1,38)=0.51$, $\left.P=0.479, \eta^{2}=0.013\right)$.

A post hoc power analysis was conducted using the software package, $G^{*}$ Power [43]. The sample size of 40 was used for the statistical power analyses with recommended effect sizes of 0.10 (small effect), 0.25 (medium effect), and 0.40 (large effect). The alpha level used for this analysis was $P<.05$. The post hoc analyses revealed that the statistical 
TABLe 2: Mean (standard deviations) for the Kusche Affective interview-revised rater interpretations of the appropriateness and quality of responses for positive and negative emotions and basic and complex emotions.

\begin{tabular}{|c|c|c|c|c|c|c|c|c|}
\hline & \multicolumn{2}{|c|}{$\begin{array}{c}\text { Positive } \\
\text { (happy, love, and proud) }\end{array}$} & \multicolumn{2}{|c|}{$\begin{array}{c}\text { Negative } \\
\text { (sad, jealous, and nervous) }\end{array}$} & \multicolumn{2}{|c|}{$\begin{array}{c}\text { Basic } \\
\text { (happy, sad, and love) }\end{array}$} & \multicolumn{2}{|c|}{$\begin{array}{c}\text { Complex } \\
\text { (proud, jealous, and nervous) }\end{array}$} \\
\hline & Appropriate & Good quality & Appropriate & Good quality & Appropriate & Good quality & Appropriate & Good quality \\
\hline Boys & $\begin{array}{c}43.00 \\
(10.03)\end{array}$ & $\begin{array}{l}15.96 \\
(3.95)\end{array}$ & $\begin{array}{l}43.68 \\
(8.26)\end{array}$ & $\begin{array}{l}15.92 \\
(3.34)\end{array}$ & $\begin{array}{l}45.92 \\
(8.65)\end{array}$ & $\begin{array}{l}17.20 \\
(3.84)\end{array}$ & $\begin{array}{c}40.76 \\
(10.20)\end{array}$ & $\begin{array}{l}14.68 \\
(4.05)\end{array}$ \\
\hline Girls & $\begin{array}{l}49.47 \\
(5.33)\end{array}$ & $\begin{array}{l}18.80 \\
(2.46)\end{array}$ & $\begin{array}{l}47.27 \\
(4.43)\end{array}$ & $\begin{array}{l}17.27 \\
(1.91)\end{array}$ & $\begin{array}{l}51.20 \\
(3.86)\end{array}$ & $\begin{array}{l}18.87 \\
(1.81)\end{array}$ & $\begin{array}{l}45.53 \\
(5.55)\end{array}$ & $\begin{array}{l}17.20 \\
(2.48)\end{array}$ \\
\hline
\end{tabular}

power for this study was 0.09 for detecting a small effect, 0.34 for detection of a moderate effect size and 0.69 for the detection of a large effect size. Thus, there was less than adequate power (i.e., power $<0.80$ ) to detect any interaction effects, given the small sample size.

3.2. Color Preferences. In Part 1 of the color assessment tasks, color preferences were rated independently by the children using a five-point smiley-face Likert scale (ranging from "very happy" to "very unhappy") to determine their emotional response for each of the ten colors: red, orange, yellow, green, blue, purple, pink, white, brown, and black.

Overall, boys were more indecisive than girls (saying "I do not know" more often) when a color was presented and were less willing (or able) to rate a color as making them feel either happy or unhappy $(t(37)=2.56, P=0.02)$.

Of those children who decided that a color made them feel happy or unhappy, there were no significant differences in rating orange, yellow, purple, or pink as either happy or unhappy. However, black, white, red, green, and brown were significantly more likely to be rated as an unhappy color (black: $\chi^{2}=11.11, P<0.001$; white: $\chi^{2}=15.11$, $P<0.001$; red: $\chi^{2}=4.50, P=0.034$; green: $\chi^{2}=3.90, P=$ 0.049; brown: $\left.\chi^{2}=16.03, P<0.001\right)$ with only blue being significantly rated as a happy color $\left(\chi^{2}=6.53, P=0.011\right)$.

When looking at individual colors and gender differences, purple and pink ratings showed significant gender differences (purple: $\chi^{2}(1,36)=20.61, P<0.001$; pink: $\left.\chi^{2}(1,37)=15.71, P<0.001\right)$ with girls rating purple and pink as a happy color and boys rating as an unhappy color. Red and brown revealed marginally significant gender differences with girls rating red as unhappy and boys rating red as a happy color $\left(\chi^{2}(1,32)=3.14, P=0.076\right)$, whereas girls were more likely to rate brown as unhappy, compared to boys $\left(\chi^{2}(1,33)=2.99, P=0.084\right)$. Other colors (orange, yellow, black, white, blue, and green) revealed no significant gender differences. Percentages of gender and color preferences, along with chi-square, probability $(P)$ and Phi (effect size) values can be seen in Table 3.

3.3. Color-Emotion Associations. Part 2 of the color assessment tasks required the children to pick a color after being read a story containing the six emotions used in the Kusche Affective Interview (happy, sad, love, proud, jealous, nervous). The colors chosen (if any) were cross-referenced with the color preferences above ("was this a color that made them feel happy or unhappy?"). For example, if a color

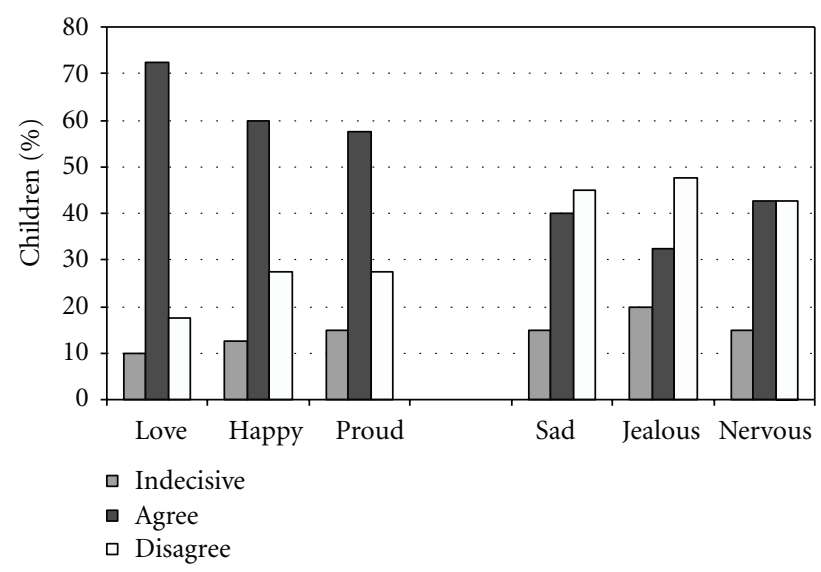

FIgURE 1: Associations between color preferences and coloremotion links within a storytelling situation.

was chosen for a story depicting a negative (sad, jealous, and nervous) emotion, it was established whether the child had stated that this color made them feel unhappy in Part 1. Similarly, if the emotion was positive (happy, proud, and love), it was established whether the child had stated that this color made them happy in Part 1. In this way, we could determine whether the children were establishing color-emotion links between the individual emotions and the grouped positive/negative emotions as used in the Kusche Affective Interview. Figure 1 represents these findings.

Children were more consistent in assigning a previously rated happy color with a positive emotion (happy, proud, and love). Significant differences were found between those children who chose a color for a positive emotion that they had previously rated as making them feel happy (agreement) compared with those children who chose a color for a positive emotion that they had previously rated as making them feel unhappy (disagreement). Agreement/disagreement ratings for negative emotions were more inconsistent with more disagreements between color choice and emotion-color links. Results for these findings can be found in Table 4 .

3.4. Comparisons of Color Assessment Task and Kusche Affective Interview. We investigated whether children who were more able to assign happy-preferred colors to positive emotions in the color assessment tasks were also able to provide more appropriate and good quality answers for the positive emotions in the Kusche Affective Interview 
TABLE 3: Percentages of children who expressed a preference for colors as happy or unhappy.

\begin{tabular}{lcccccccccc}
\hline & Red & Orange & Yellow & Green & Blue & Purple & Pink & White & Brown & Black \\
\hline Happy & & & & & & & & & & \\
$\quad$ Boys & 45.0 & 31.6 & 37.5 & 35.0 & 73.7 & 8.3 & 12.5 & 13.6 & 27.8 & 28.6 \\
$\quad$ Girls & 8.3 & 57.1 & 50.0 & 27.3 & 72.7 & 91.7 & 84.6 & 23.1 & 0.0 & 13.3 \\
\hline Unhappy & & & & & & & & & & \\
$\quad$ Boys & 55.0 & 68.4 & 62.5 & 65.0 & 26.3 & 91.7 & 87.5 & 86.4 & 72.2 & 71.4 \\
$\quad$ Girls & 91.7 & 42.9 & 50.0 & 72.7 & 27.3 & 8.3 & 15.4 & 76.9 & 100.0 & 86.7 \\
\hline$\chi^{2}$ & 3.14 & 0.54 & 0.08 & 0.002 & 0.00 & 20.60 & 15.71 & 0.06 & 2.99 & 0.46 \\
$P$ & 0.076 & 0.463 & 0.783 & 0.969 & 1.00 & $<0.001^{* * *}$ & $<0.001^{* * *}$ & 0.801 & 0.084 & 0.498 \\
Phi & -0.383 & 0.233 & 0.125 & -0.79 & -0.010 & 0.818 & 0.710 & 0.121 & -0.386 & -0.181 \\
\hline$* * *$
\end{tabular}

TABLE 4: Agreements and disagreements of emotions with color preference.

\begin{tabular}{lcccccccc}
\hline & \multicolumn{3}{c}{ Positive emotions } & & \multirow{2}{*}{ Total positive } & \multicolumn{3}{c}{ Negative emotions } \\
& Happy & Love & Proud & & Sad & Jealous & Nervous \\
\hline Chi-square & 4.829 & 13.440 & 4.235 & 6.400 & 0.118 & 1.125 & 0.000 & 1.600 \\
$P$ value & $0.028^{*}$ & $<0.001^{* * *}$ & $0.040^{*}$ & $0.011^{*}$ & 0.732 & 0.289 & 1.000 & 0.206 \\
\hline$*$
\end{tabular}

${ }^{*} P<0.05,{ }^{* *} P<0.01,{ }^{* * *} P<0.001$.

responses. There were no associations with either the appropriateness or quality, of responses for love (appropriate: $r=0.25, P=0.121$; quality: $r=0.22, P=0.183$ ) and proud (appropriate: $r=-0.12, P=0.453$; quality: $r=-0.17$, $P=0.285)$. There was a marginally significant association for happy (appropriate: $r=0.31, P=0.052$; quality: $r=0.24$, $P=0.183$ ) with those children who associated a happy color with a happy emotion providing a more appropriate responses to the identification of happy emotions in the Kusche Affective Interview.

\section{Discussion}

This study investigated emotional understanding and coloremotion associations in boys and girls, aged 7-8 years. The six emotions presented for the purposes of analysis (happy, proud, love, sad, nervous and jealous) were grouped into positive (happy, proud, and love) and negative (sad, nervous, and jealous) and basic (sad, happy, and love) and complex (proud, nervous, and jealous).

When comparing emotion groupings as negative and positive or basic and complex, both boys and girls were able to produce more appropriate and better quality responses for basic emotions when compared to complex emotions, but there were no overall differences in the children's ability to produce appropriate and high quality responses for positive as compared to negative emotions.

Consistent with previous findings [18, 28], girls were able to provide more appropriate and better quality responses to all the emotions presented, even though there were no significant differences in underlying expressive verbal vocabulary between boys and girls in this study. The girls consistently appeared to be able to understand and communicate emotion more effectively than their male counterparts. Boys were also significantly more indecisive than girls in being able to state whether a color made them feel happy or unhappy. This may be indicative of a greater emotional understanding and higher emotional maturity in girls even at this young age, with boys having a less developed understanding of which emotions provoke certain behaviours in individuals [44].

No interaction effects between gender and emotion responses were found and this, in part, may be due to the reduced power resulting from the small sample size. However, although we would recommend the inclusion of a larger sample size in a future study, we can only speculate whether there would be additional significant interaction effects within a larger population.

In those children who rated a color as making them feel happy or unhappy, more colors were significantly rated as unhappy (black, white, red, green, and brown) than happy (blue). Children equally rated orange, yellow, purple, and pink. A more detailed gender analysis revealed significant gender differences for pink and purple (girls rating as happy colors, boys rating as unhappy colors), with marginally significant findings for red and brown (boys rating as happy colors, girls rating as unhappy colors). No specific gender differences were noted for yellow, orange, white, blue, green and black.

Differences in associations for pink and brown may be indicative of a stereotypical representation of color-gender associations [30], although this did not occur with the traditionally stereotyped blue which boys and girls rated as a happy color. Interestingly, the school uniform was blue, indicating that familiarity and personal associations can override the effect of stereotypical color preferences. Other colors such as red and green can convey several meanings and associations, and therefore emotional ambivalence. These findings emphasize that the importance of understanding personal color-emotion affiliations in any interpretation of 
color use and the development of any future definitive assessments of color use need to consider both gender and context.

A further methodological point to consider is that colors vary on more than one dimension. For example, in using Munsell dimensions, they vary in hue, value (brightness), and chroma (saturation). Any results obtained may, therefore, be due to variations in color on any one dimension or combination of dimensions. Within our study, "happy" colors tended to have a higher value and chroma rating which could have been influential in a child's interpretation of the cards in relation to particular emotions. In addition, comparison of cards and corresponding pens could also have led to differences in interpretation between the two parts of our study (e.g., some pens matching corresponding colour cards on all color dimensions better than others). However, as all children had access to the same color cards and corresponding color marker pens, it is likely that the gender differences observed within our study remain a valid finding. However, in order to make direct comparisons between this and past or future studies, further consideration of all the dimensions of colors (hue, brightness, and saturation) needs to be incorporated. This is especially true in relation to colors that convey several meanings (e.g., red and green) as variations in color notation (differences in brightness, for example) could be a confounding factor that could significantly affect results.

When relating color preference to the emotions of characters within a story context, children were more able to assign preferred colors to positive emotions (happy, love, and proud) than negative emotions (sad, jealous, and nervous). This suggests that there are specific color-emotion schemas being established within this age group as noted previously [30]. One possible explanation of these findings is that most young children are protected and exposed to more positive environments in their early years; environments that are often linked with bright and vibrant positive colors. It is possible, therefore, that the children in this study had established strong positive color-emotion links though their early life experiences [34]. Negative environments, however, are less encountered by young children and therefore negative coloremotion links may not be established until later in life. Findings in this study are consistent with this explanation. However, alternative explanations are also possible. For example, although a child may like a color for personal reasons (e.g., green), they understand that this color can be linked to a negative emotion (e.g., jealousy), creating more emotional ambivalence with negative color-emotion associations. In this case, a disagreement between color preference and assignment to an emotion within a story may not necessarily indicate weaker emotional understanding. Further study is necessary to understand why children prefer some colors to others and their subsequent links to specific emotional states.

There were no significant relationships between the Kusche Affective Interview ratings and the color-emotions preferences. The emotion of happiness alone showed a weak association. Of all the emotions included within the study, "happy" is the most basic, least contentious, and possibly most encountered expression of emotion experienced by these young children. It is reasonable, therefore, that the strongest associations would be evident with this emotion, compared to the more complex emotions such as "proud". In addition, the methodology used within this study needs to be considered. Although tests were designed to be as objective as possible, it is almost impossible in studies of this nature to rule out all subjective interpretations. The ratings of appropriateness and quality of responses, the conveyance of an emotion through storytelling, and the choice of initial colors for presentation can all lead to some degree of subjective error.

Recent research indicates that an increased emotional understanding can increase school attendance, promote higher motivation, increase self-esteem $[1,45]$, and improve academic performance [46]. With girls consistently displaying greater emotional understanding than boys (both in this and previous studies), there is a need for more gender-specific attention to be given to interventions regarding emotional literacy and understanding.

It is also important to consider our findings when working with young children, especially in relation to those children presenting with emotional disorders or social and affective problems. The lack of associations with color interpretation indicates that, providing color preferences are taken into account, color could be a useful tool for all children to use as it does not rely on the verbal expression of emotional states. Interpretation of color use by those children presenting with emotional problems and comparisons with color use interpretations of "normally" developing children may provide clinicians with important information about their emotional associations. In the clinical context, color use can assist interventions by activating and promoting positive emotions, which may then provide heightened therapeutic and preventative effects and so further enhance motivation towards treatment [47].

In the same way that commercial organisations are aware of the effect of color in the presentation of merchandise, professionals working with children must also apply similar consideration in assessment and analysis of color-emotion associations. Commonly used assessment batteries such as the Mayer-Salovey-Caruso Emotional Intelligence Test (MSCEIT), a measurement of emotional intelligence abilities, involve a number of emotion-related problem solving tasks [48]. Throughout the MSCEIT there is exposure to color, whether this is by illustration or independent measure, for example tests to assess the ability to perceive emotions utilising artistic designs and landscapes, or when an individual is asked to rate and identify particular feelings elicited by the artistic design [49]. Our study implies that it is important within such measures to consider the possibility of subtle individual and gender differences due to the unique interpretation of color or the emotion elicited from colorful illustrations.

From a clinical perspective, there is a considerable advantage in allowing a child to have an individual voice through drawing and/or coloring. The analysis of such creativity is important to provide information for all professionals working with children as the development of a greater awareness and understanding of how children view and perceive the world can help in the future production of effective 
educational and clinical interventions and treatments [25]. However, there needs to be a greater knowledge of the developmental use of color [29] and the interpretation from a child's perspective. As with the documented developmental stages of the acquisition of drawing ability, it is possible that color use and emotion associations follows a similar path.

In conclusion, the study of color-emotion associations is a complex area open to the subjective interpretation. An awareness of the potential impact and influence of personal color association with emotion is an additional factor to consider within educational or clinical settings and is particularly important where direct use of color within assessment situations is being considered and used.

\section{References}

[1] K. Weare and G. Gray, "What works in developing children's emotional and social competence and wellbeing?" Research Report RR456, Department for Education and Skills, London, UK, 2003.

[2] A. L. Cutting and J. Dunn, "Theory of Mind, emotion understanding, language, and family background: individual differences and interrelations," Child Development, vol. 70, no. 4, pp. 853-865, 1999.

[3] Ofsted, Healthy minds, Ofsted Better Education and Care, 117, Reference number HMI, 2457, 2005.

[4] N. Bauminger, H. S. Edelsztein, and J. Morash, "Social information processing and emotional understanding in children with LD," Journal of Learning Disabilities, vol. 38, no. 1, pp. 45-61, 2005.

[5] A. L. Seja and S. W. Russ, "Children's fantasy play and emotional understanding," Journal of Clinical Child and Adolescent Psychology, vol. 28, no. 2, pp. 269-277, 1999.

[6] P. N. Lopes, P. Salovey, and R. Straus, "Emotional intelligence, personality, and the perceived quality of social relationships," Personality and Individual Differences, vol. 35, no. 3, pp. 641658, 2003.

[7] J. W. Payton, D. M. Wardlaw, P. A. Graczyk, M. R. Bloodworth, C. J. Tompsett, and R. P. Weissberg, "Social and emotional learning: a framework for promoting mental health and reducing risk behavior in children and youth," Journal of School Health, vol. 70, no. 5, pp. 179-185, 2000.

[8] Speaking Out, Child health strategy briefing paper 19: healthy lives, brighter futures: the strategy for children and young peoples health, 2009, www.childrenengland.org.uk.

[9] Child and Adolescent Mental Health Service, Children and young people in mind: the final report of the National CAMHS review, 2008, http://webarchive.nationalarchives.gov .uk/20081230004520/publications.dcsf.gov.uk/eorderingdownload/camhs-review.pdf.

[10] T. Woolfe, S. C. Want, and M. Siegal, "Signposts to development: theory of mind in deaf children," Child Development, vol. 73, no. 3, pp. 768-778, 2002.

[11] J. H. Flavell, "Cognitive development: children's knowledge about the mind," Annual Review of Psychology, vol. 50, pp. 2145, 1999.

[12] M. A. Southam-Gerow and P. C. Kendall, "Emotion regulation and understanding: implications for child psychopathology and therapy," Clinical Psychology Review, vol. 22, no. 2, pp. 189-222, 2002.

[13] A. Toomela, "Drawing as a verbally mediated activity: a study of relationships between verbal, motor, and visuospatial skills and drawing in children," International Journal of Behavioral Development, vol. 26, no. 3, pp. 234-247, 2002.

[14] R. Vasta, Six Theories of Child Development: Revised Formulations and Current Issues, Jessica Kingsley, Bristol, Pa, USA, 1992.

[15] S. Caillies and S. Le Sourn-Bissaoui, "Children's understanding of idioms and theory of mind development," Developmental Science, vol. 11, no. 5, pp. 703-711, 2008.

[16] R. Saxe, S. Carey, and N. Kanwisher, "Understanding other minds: linking developmental psychology and functional neuroimaging," Annual Review of Psychology, vol. 55, pp. 87-124, 2004.

[17] L. Feldman Barrett, R. D. Lane, L. Sechrest, and G. E. Schwartz, "Sex differences in emotional awareness," Personality and Social Psychology Bulletin, vol. 26, no. 9, pp. 1027-1035, 2000.

[18] S. L. Bosacki and C. Moore, "Preschoolers' understanding of simple and complex emotions: links with gender and language," Sex Roles, vol. 50, no. 9-10, pp. 659-675, 2004.

[19] J. R. Brown and J. Dunn, "Continuities in Emotion Understanding from Three to Six Years," Child Development, vol. 67, no. 3, pp. 789-802, 1996.

[20] J. T. Laak, M. De Goede, A. Aleva, and P. Van Rijswijk, "The draw-a-person test: an indicator of children's cognitive and socioemotional adaptation?" Journal of Genetic Psychology, vol. 166, no. 1, pp. 77-93, 2005.

[21] N. S. Bekhit, G. V. Thomas, and R. P. Jolley, "The use of drawing for psychological assessment in Britain: survey findings," Psychology and Psychotherapy: Theory, Research and Practice, vol. 78, no. 2, pp. 205-217, 2005.

[22] M. Catte and M. V. Cox, "Emotional indicators in children's human figure drawings," European Child and Adolescent Psychiatry, vol. 8, no. 2, pp. 86-91, 1999.

[23] R. P. Jolley, K. Fenn, and L. Jones, "The development of children's expressive drawing," British Journal of Developmental Psychology, vol. 22, no. 4, pp. 545-567, 2004.

[24] S. I. Kim, J. Bae, and Y. Lee, "A computer system to rate the color-related formal elements in art therapy assessments," Arts in Psychotherapy, vol. 34, no. 3, pp. 223-237, 2007.

[25] P. J. Pridmore and R. G. Lansdown, "Exploring children's perceptions of health: does drawing really break down barriers?" Health Education Journal, vol. 56, no. 3, pp. 219-230, 1997.

[26] T. Sakaki, Y. Ji, and S. Z. Ramirez, "Clinical application of color inkblots in therapeutic storytelling," Arts in Psychotherapy, vol. 34, no. 3, pp. 208-215, 2007.

[27] M. V. Cox, The Pictorial World of the Child, Cambridge University Press, Cambridge, UK, 2005.

[28] E. Burkitt, M. Barrett, and A. Davis, "Children's colour choices for completing drawings of affectively characterised topics," Journal of Child Psychology and Psychiatry and Allied Disciplines, vol. 44, no. 3, pp. 445-455, 2003.

[29] R. Lev-Wiesel and S. Daphna-Tekoha, "The self-revelation through color technique: understanding clients' relations with significant others, silent language, and defense mechanisms through the use of color," American Journal of Art Therapy, vol. 39, no. 2, pp. 35-41, 2000.

[30] C. J. Boyatzis and R. Varghese, "Children's emotional associations with colors," The Journal of Genetic Psychology, vol. 155, no. 1, pp. 77-85, 1994.

[31] A. J. Elliot, M. A. Maier, A. C. Moller, R. Friedman, and J. Meinhardt, "Color and psychological functioning: the effect of red on performance attainment," Journal of Experimental Psychology, vol. 136, no. 1, pp. 154-168, 2007. 
[32] J. Gross and H. Hayne, "Drawing facilitates children's verbal reports of emotionally laden events," Journal of Experimental Psychology, vol. 4, no. 2, pp. 163-179, 1998.

[33] M. R. Zentner, "Preferences for colours and colour-emotion combinations in early childhood," Developmental Science, vol. 4, no. 4, pp. 389-398, 2001.

[34] L. N. Niec and S. W. Russ, "Children's internal representations, empathy, and fantasy play: a validity study of the SCORS-Q," Psychological Assessment, vol. 14, no. 3, pp. 331-338, 2002.

[35] V. S. Gregorian, A. Azarian, M. B. DeMaria, and L. D. McDonald, "Colors of disaster: the psychology of the "black sun"' Arts in Psychotherapy, vol. 23, no. 1, pp. 1-14, 1996.

[36] S. W. Russ and E. D. Schafer, "Affect in fantasy play, emotion in memories, and divergent thinking," Creativity Research Journal, vol. 18, no. 3, pp. 347-354, 2006.

[37] P. Valdez and A. Mehrabian, "Effects of color on emotions," Journal of Experimental Psychology, vol. 123, no. 4, pp. 394409, 1994.

[38] T. W. Whitfield and T. J. Wiltshire, "Color psychology: a critical review," Genetic, Social, and General Psychology Monographs, vol. 116, no. 4, pp. 385-411, 1990.

[39] C. A. Kusche, R. Beilke, and M. T. Greenberg, Seattle Personality Questionnaire For Young School-Aged Children, University of Washington, Department of Psychology, Seattle, Wash, USA, 1988.

[40] Munsell, The Munsell Book of Color: Glossy Finish Collection, Munsell Color, Baltimore, Md, USA, 1988.

[41] J. Elkin, The Puffin Book of Twentieth-Century Children's Stories, Puffin Books, 1992.

[42] R. Brownell, Ed., Expressive One-Word Picture Vocabulary Test: Manual, Academic Therapy Publications, Novato, Calif, USA, 3rd edition, 2000.

[43] F. Faul, E. Erdfelder, A. G. Lang, and A. Buchner, "G* Power 3: a flexible statistical power analysis program for the social, behavioral, and biomedical sciences," Behavior Research Methods, vol. 39, no. 2, pp. 175-191, 2007.

[44] P. Muris, P. Steerneman, C. Meesters et al., "The TOM test: a new instrument for assessing theory of mind in normal children and children with pervasive developmental disorders," Journal of Autism and Developmental Disorders, vol. 29, no. 1, pp. 67-80, 1999.

[45] P. Qualter, H. E. Whiteley, J. M. Hutchinson, and D. J. Pope, "Supporting the development of Emotional Intelligence skills to ease the transition from primary to high school," Educational Psychology in Practice, vol. 23, pp. 79-95, 2007.

[46] P. Qualter, K. Gardner, D. Pope, J. Hutchinson, and H. E. Whiteley, "Ability emotional intelligence, trait emotional intelligence, and academic success in British secondary schools: a 5 year longitudinal study," Learning and Individual Differences, vol. 22, no. 1, pp. 83-91, 2012.

[47] C. E. Izard, "Translating emotion theory and research into preventive interventions," Psychological Bulletin, vol. 128, no. 5, pp. 796-824, 2002.

[48] N. R. Skaar, “Test review: Mayer, J.D., Salovey, P., Caruso, D., (2002): Mayer-Salovey-Caruso Emotional Intelligence Test. Toronto, Canada: Multi-Health Systems," Assessment for Effective Intervention, vol. 33, pp. 47-50, 2007.

[49] M. A. Brackett and P. Salovey, "Measuring emotional intelligence with the Mayer-Salovery-Caruso Emotional Intelligence Test (MSCEIT)," Psicothema, vol. 18, no. 1, pp. 34-41, 2006. 


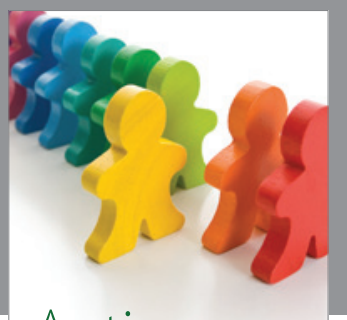

Autism

Research and Treatment
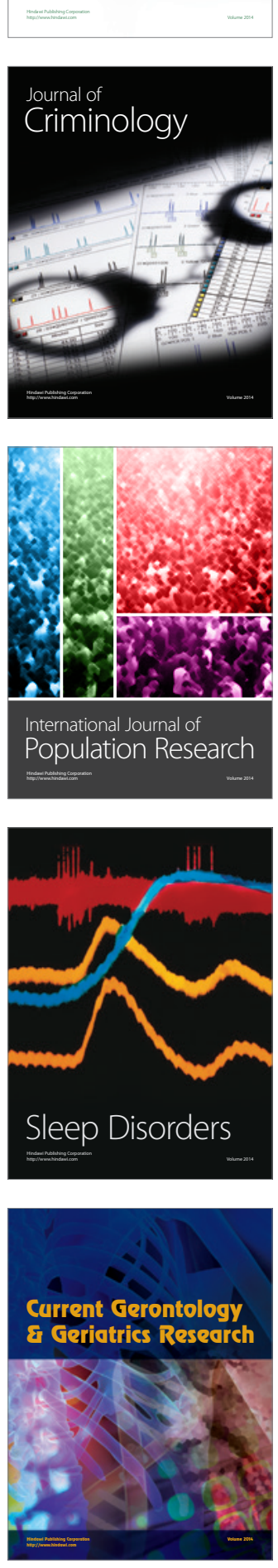
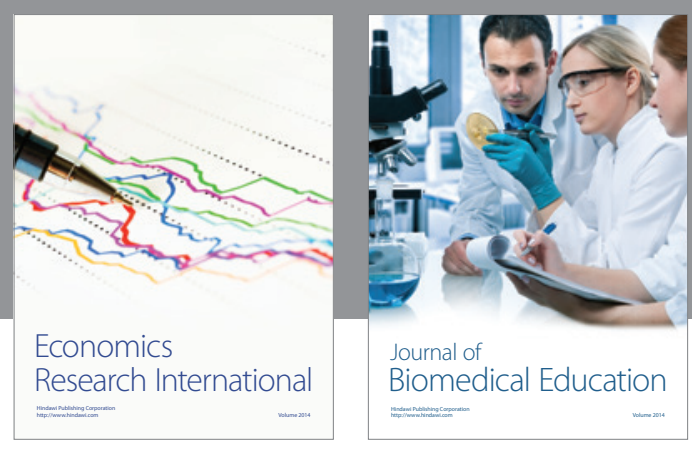

Journal of

Biomedical Education

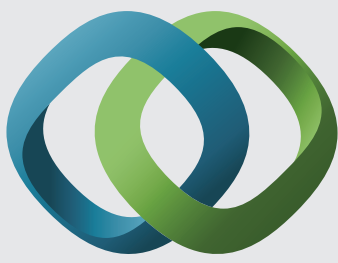

\section{Hindawi}

Submit your manuscripts at

http://www.hindawi.com
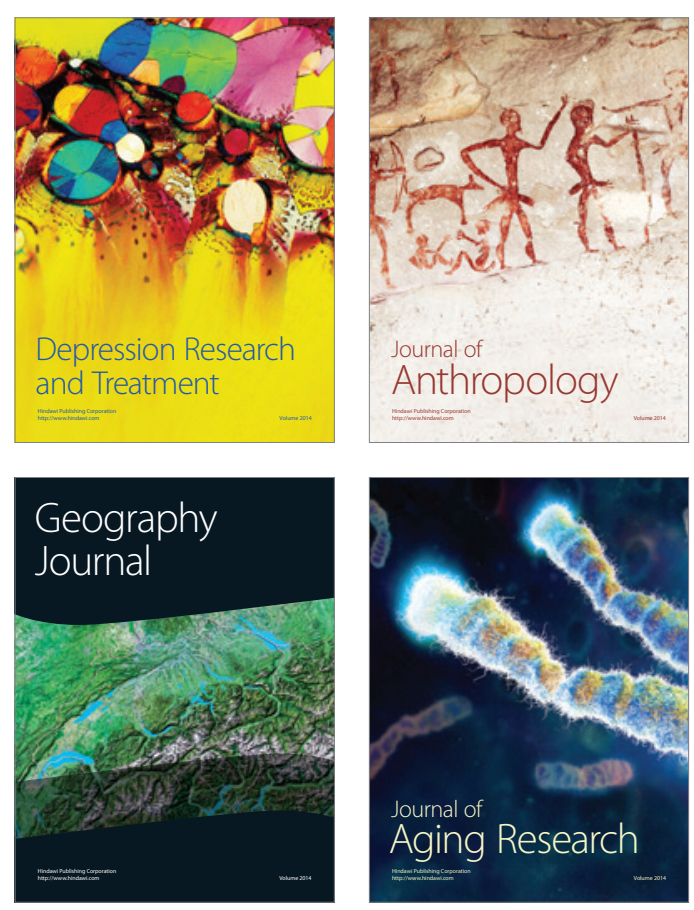

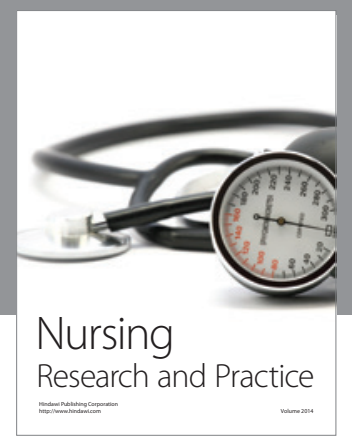

Nursing

Research and Practice

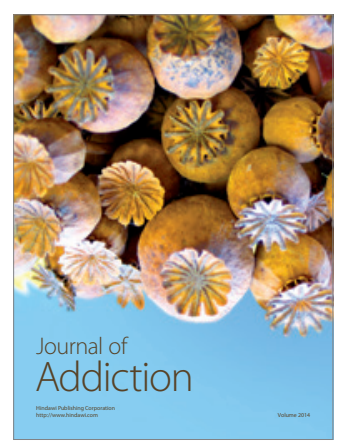

Child Development

Research

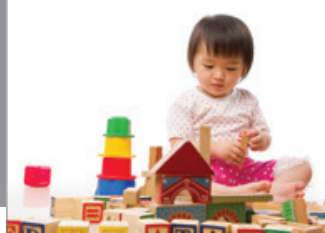

迥
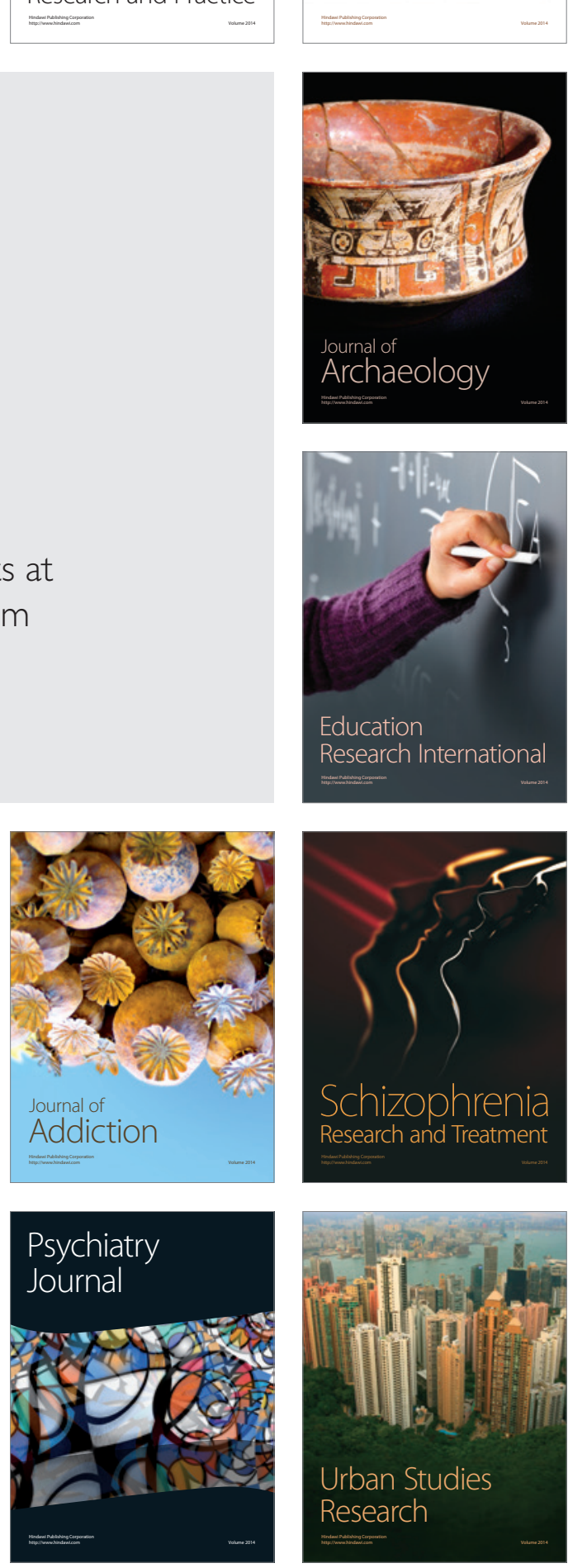